\title{
Patient Satisfaction With Caring at a District Hospital in Malawi
}

\author{
Brian Nkwinda ${ }^{1}$, Wanda Jacobs ${ }^{2} \&$ Charlene Downing ${ }^{3}$ \\ ${ }^{1}$ Post graduate student (MCur), Department of Nursing, University of Johannesburg, South Africa \\ ${ }^{2}$ Lecturer and supervisor (DCur), Department of Nursing, University of Johannesburg, South Africa \\ ${ }^{3}$ Senior lecturer and co-supervisor (DCur), Department of Nursing, University of Johannesburg, South Africa \\ Correspondence: Charlene Downing, Department of Nursing, Faculty of Health Sciences, University of \\ Johannesburg, Johannesburg, South Africa. Tel: 27-011-559-9063. E-mail: charlened@uj.ac.za
}

Received: September 22, 2018 Accepted: November 15, 2018 Online Published: December 13, 2018

doi:10.5539/gjhs.v11n1p15 URL: https://doi.org/10.5539/gjhs.v11n1p15

\begin{abstract}
Purpose: The purpose of this study was to investigate and understand patient satisfaction with caring at a district hospital in Malawi.

Materials and Methods: The study used a mixed methods design, employing the sequential explanatory strategy. A total of 120 adult patients completed a survey questionnaire (phase one), and of these, two patients were followed up with individual interviews (phase two).

Results: Data were analyzed using statistical procedures, thematic analysis and an integration process of quantitative and qualitative findings. Highest patient satisfaction $(90.6 \% ; \mathrm{M}=4.53 ; \mathrm{SD}=0.879)$ occurred with nurses' presence; while lowest satisfaction $(37.4 \% ; \mathrm{M}=1.87 ; \mathrm{SD}=1.710)$ was seen with patient teaching. Patients' lived experiences revealed that nurses' demonstration of presence and professional proficiency were critical to caring.
\end{abstract}

Unique Contribution to Theory, Practice and Policy: To enhance improved caring, there was a need for nurses to increase personal presence, promote patient involvement in decision-making, and demonstrate competent confidence.

Keywords: caring, district hospital, Malawi, mixed methods, patient satisfaction

\section{Introduction}

Caring is the core of nursing (Qiuting, 2013; Watson, 1979) and forms the basis for an inter-subjective relationship between the patient and the nurse (Wu \& Volker, 2012). Failure to provide optimum care diminishes quality and negatively impacts on patient outcomes including patient satisfaction (Kim et al., 2017). Patients' satisfaction is regarded as a major determinant of healthcare quality (Kvist, Voutilainen, Mäntynen, \& Vehviläinen-Julkunen, 2014), and a clear insight into patients' self-reports of their satisfaction with care may help in efforts to improve the care (Aiken et al., 2012).

\subsection{Literature Overview}

\subsubsection{Attributes of Caring}

Caring is described with reference to cognitive actions, behaviors, techniques, processes, or patterns that are culturally learned to help an individual, family or community improve or maintain a healthy condition (Smith, 2013). When quality of care is good, patients tend to be satisfied with it (Kim et al., 2017). Three attributes have been identified as being key to caring: professional knowledge and skills, trusting nurse-patient relationship, and promotion of human dignity.

\subsubsection{Professional Knowledge and Skills}

Professional knowledge and skills comprise the theory, practice and experience of the nurse, (Sumner, 2012). They are the authority that mandates the nurse to render care (Papastavrou et al., 2012). Professional knowledge and skills demonstrate the nurse's competence (Shrestha, Petrini \& Turale, 2013), and when intertwined with positive personality characters, they help the nurse demonstrate professional maturity by conveying caring, loving kindness, and equanimity (Smith, 2013). Knowledge deficit and lack of skills among nurses were found to be the cause for unwarranted changes of filters, removal of machines, and failure to troubleshoot equipment in continuous renal 
replacement therapy (Przybyl, Androwich, \& Evans, 2015), not knowing what to do or say to patients (Baillie, Cox, \& Merritt, 2012), and development of a negative attitude towards nursing (Baillie et al., 2012; Nguyen, Yates, \& Osborne, 2014).

\subsubsection{Trusting Nurse-Patient Relationship}

Building a trusting nurse-patient relationship is vital to securing the patient's active engagement with the healthcare experience (Phillips-Salimi, Haase, \& Kooken, 2011). Patients who are actively involved in a trusting nurse-patient relationship have been found to experience increased adherence to treatment protocols (Elder et al., 2012; Blackstock, Addison, Brennam, \& Alao, 2012), increased likelihood of lifestyle and behavioral change (Jones, Carson, Bleich, \& Cooper, 2012), and higher patient satisfaction with care (Shan et al., 2016; Bohnert, Zivin, Welsh, \& Kilbourne, 2011), leading to improved healthcare outcomes. In addition, Brumpton et al., (2013) ascertained the therapeutic effect of a trusting nurse-patient relationship. They found that chronic stress acted as a pathologic trigger in asthma incidents among adult patients, and by controlling stress through the trusting nurse-patient relationship, asthma incidents were reduced. Winning patients' trust, however, takes deliberate effort by the provider (Murray \& McCrone, 2015). Meyer, Ward and Jiwa (2012) posit that morals and ethics are critically important to offset power imbalances associated with the patient's vulnerability.

\subsubsection{Promoting Human Dignity}

Humans have a desire to maintain dignity at all cost, however, vulnerability from illness occasionally demeans their will and predisposes them to a loss of their dignity (Ferri, Muzzalupo, \& Lorenzo, 2015). Studies indicate that patients who are treated with dignity experience reduced stress (Warner, Saxton, Indig, Fahy, \& Hovart, 2012), greater satisfaction (Lin \& Lin, 2011), increased comfort, and enhanced recovery (Baillie \& Gallagher, 2011). Dignity is, therefore, an essential element in healthcare. Perceptions of care quality do not simply depend on treatment outcomes, but also on the manner in which care is delivered (Ferri et al., 2015). In caring, dignity as a concept has been associated with respect, privacy, justice, autonomy, respectful communication and emotional support conferred upon humans (Ferri et al., 2015; Lin \& Tsai, 2011; Tadd et al., 2011). In contrast, undignified care is characterized by individual dehumanization and objectification, the use of humiliating and abusive language, lack of focus, and the promotion of individual invisibility and disempowerment (Tadd et al., 2011). Respecting patients involves honoring their beliefs, aspirations, commitments and choices, understanding their abilities and limits, and promptly attending to their needs and priorities (Lin, Tsai, \& Chen, 2011; Tadd et al., 2011). Respect for patients promotes patients' autonomy and active participation in nursing care. Therefore, respecting and maintaining human dignity in patient care is a way of demonstrating a caring attitude (Ferri et al., 2015).

\subsubsection{Patient Satisfaction}

Patient satisfaction is described as the patient's attitude, perceptions or feelings towards care and the extent to which their expectations of ideal care are met when compared with the actual care received (Iftikhar et al., 2011; Rama \& Kanagaluru, 2011). Patient satisfaction has recently become a very useful outcome indicator for quality of care (Aiken et al., 2012; Kvist et al., 2014) since it represents patients' actual views on care (Al-Abri \& Al-Balushi, 2014). Also, the increasing awareness of patients' rights among healthcare users due to advancements in information and technology services has strengthened the healthcare consumerism attitude which calls for incorporating patients' views in healthcare decision-making (Souliotis et al., 2016). Despite that, however, Bjertnaes, Sjetne and Iversen (2012) posit that it would be misleading to use patients' opinions as a sole basis for subjective evaluation of care quality. Likewise, Zgierska, Rabago and Miller (2014) found that physicians under pressure to satisfy patients were lured into writing out unnecessary prescriptions, conducting needless tests, and admitting patients unnecessarily. Meanwhile, studies have shown that patients who are satisfied with care experience several positive healthcare outcomes, including increased treatment compliance (Elder et al., 2012; Blackstock et al., 2012), increased likelihood for a positive behavioral change (Jones et al., 2012), longer survival periods (Gupta, Markman, Rodeghier, \& Lis, 2012), and increased trust in healthcare providers (Bohnert et al., 2011).

Several factors have been identified that influence patient satisfaction. Among them the nature of patient-provider interaction, the level of support from the care-providers, and the nature and extent of care continuity (Kobayashi, Takemura, \& Kanda, 2011; Balfe et al., 2013; Liljeroos, Agren, Jaarsma, \& Strömberg, 2014). In the out-patient department, Carlucci, Renna and Schiuma (2013) found that provision of complete and clear medical information, attentiveness, and respecting the patient's privacy were the main factors associated with patient satisfaction. In addition, Higgins and Prigerson (2013) found that in end-of-life care, patient and care giver satisfaction were influenced by active patient and care giver involvement in decision-making, prolonging the patient's life, and preparing the patient and care givers for the patient's impending death. In Nigeria, despite being satisfied with 
overall healthcare, patients reported dissatisfaction with long waiting times, complicated hospital bureaucracy, and the high cost of services (Iloh et al., 2013). Similarly, in South Africa, patients on antiretroviral therapy (ART) reported dissatisfaction with prolonged physical examinations and insufficient HIV transmission and prevention counselling (Finkel, Adelekan, Marcus, \& Wolvaardt, 2012).

Inconsistencies have been observed regarding findings on studies investigating the influence of patient demographic variables (gender, education, age and socioeconomic status) on satisfaction with care. In Kuwait, Rouhi, Asayesh, Rahmani and Abbasi (2011) found that male patients in general- and special wards reported higher satisfaction with care than female patients. Regarding education, patients who were university graduates reported higher satisfaction than those with other qualifications. Consistent with these findings, Azizi-Fini, Mousavi Mazroui-Sabdani and Adib-Hajbaghery (2012) discovered that patient education, coupled with nurses' caring behaviors, increased patients' satisfaction. In contrast, age, gender and patients' level of education were not found to have any significant predictive value on patient satisfaction in a study by Taheri, Jahromi and Hojat (2015). These contradictory findings of various studies were an indication that more research may be required in the area of patient satisfaction and demographic variables.

\subsection{Research Problem}

However, the issues that affect patient satisfaction, the level at which patients are satisfied with nursing care, and the extent to which nurses were reported to be caring during their interactions with patients at a district hospital in Malawi, had never been documented.

\section{Methods}

The study design was mixed methods (quantitative and qualitative methods) using a sequential explanatory strategy (Creswell, 2014).

\section{Phase One (Quantitative Phase)}

In this phase, the core method was applied. It was descriptive and correlational in nature (Gray, Grove, \& Sutherland, 2017). It focused on surveying patients' satisfaction with caring. Caring nurse-patient interactions were assessed, analyzed and described in relation to patients' satisfaction (Ivankova, 2015).

\subsection{Study Participants and Setting}

Stratified sampling was used to recruit respondents. A total of 120 adult patients (18 years and older, both female and male) were recruited from four wards (female, male, TB, maternity) at the participating district hospital in Malawi. All respondents were hospitalized for at least two days prior to recruitment and volunteered to complete the questionnaire.

\subsection{Measuring Instrument and Data Collection}

Data were collected using a 58-item questionnaire divided into four sections. Section A contained five items (1-5) designed to collect respondent demographic information: gender, age, marital status, occupation, and level of education. Section B consisted of 24 items (6-29) adopted from the Caring Nurse-Patient Interactions (CNPI-23P) (Cossette et al., 2006: 198-214), scale. The CNPI-23P is divided into four dimensions namely clinical, relational, humanistic, and comforting care. Items in these four dimensions assess nurse caring from the perspective of nurse-patient interactions as evaluated by the patient. A 5-point Likert scale was used with frequency response categories 'never' (1), 'rarely' (2), 'sometimes' (3), 'often' (4), and 'always' (5). Section C comprised 25 items (30-54) adapted from the patient satisfaction instrument (PSI). The PSI has three dimensions: trust, technical-professional care, and education. The response category with the PSI was the level of agreement using the 5-point Likert scale which ranged from 'strongly disagree' (1), 'disagree' (2), 'neutral' (3), 'agree' (4), to 'strongly agree' (5). Although the PSI was developed in 1975, its usability across patient satisfaction studies is still applicable to date (Freitas, Silva, Minamaisava, Bezerra, \& Sousa, 2014). The last four questions in Section D elicited information on the general evaluation of the quality of care received by the respondents. Visual analogues (circles, emoticons and thumbs) were used across all response items. This was done in consideration of the low literacy level within the target population, and to facilitate easy understanding of the response categories among respondents.

\subsection{Reliability and Validity}

All factors of the CNPI-23P and the PSI demonstrated acceptable levels of internal consistency. Cronbach's alpha coefficient scores for CNPI-23P ranged from 0.710 to 0.905 and from 0.712 to 0.918 for the PSI. In addition, despite being multidimensional, each dimension of the CNPI-23P and the PSI were unique and no single dimension demonstrated bi-dimensionality. Conclusions derived from the study were based on patterns observed 
in the data.

\subsection{Data Analysis}

Statistical analysis procedures included descriptives, factor analysis, correlation analysis, and reliabilities.

\subsection{Findings}

\subsubsection{Respondents' Characteristics}

Table 1 shows respondents' characteristics in terms of gender, age and marital status.

Table 1. Participants' characteristics: gender, age and marital status

\begin{tabular}{lll}
\hline & Number & \% \\
\hline Gender & 105 & 87.5 \\
Female & 15 & 12.5 \\
Male & & \\
\hline Age & 31.72 & \\
Average age & 12.23 & \\
Standard deviation & & 9.2 \\
\hline Marital status & 11 & 73.3 \\
Divorced & 88 & 2.5 \\
Married & 3 & 10.8 \\
Separated & 13 & 4.2 \\
Single & 5 & \\
Widowed & & \\
\hline
\end{tabular}

Of all 120 respondents, $87.5 \%(n=105)$ were women and $12.5 \%(n=15)$ were men. The age distribution of all respondents ranged from 18 to 70 . The majority of respondents, $73.3 \%(n=88)$, were married, $10.8 \%(n=13)$ were single, $9.2 \%(\mathrm{n}=11)$ were divorced, $4.2 \%(\mathrm{n}=5)$ were widowed, and $2.5 \%(\mathrm{n}=3)$ were separated.

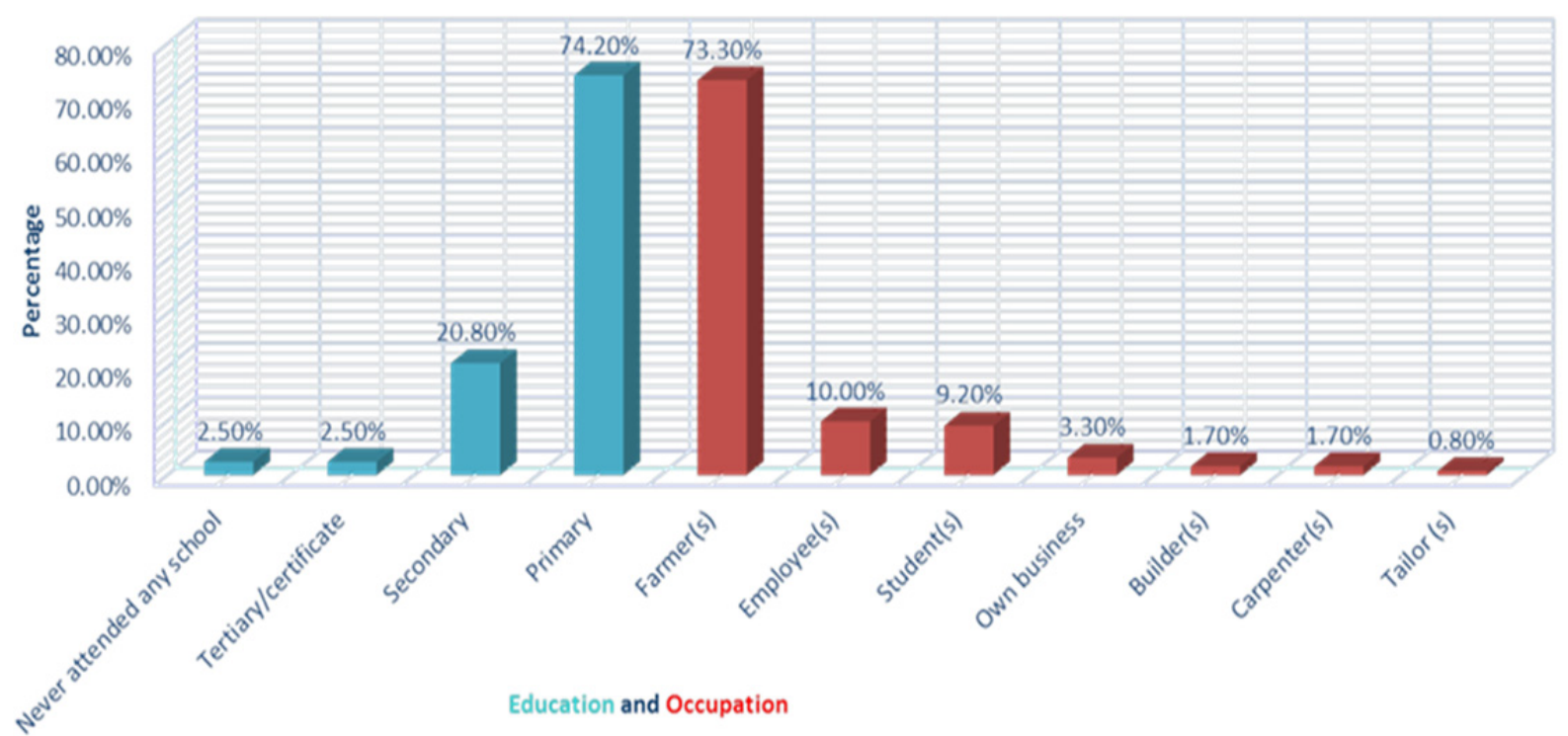

Figure 1. Depicts respondents' characteristics in terms of level of education and occupation 
Of the total number of respondents $(n=120)$, the majority, $73.3 \%(n=88)$, were farmers. Few others, $10.0 \%(n=12)$, were business people, $9.2 \%(n=11)$ were students, and $3.3 \%(n=4)$ were technical professional employees. Craft workmanship was very low with only $1.7 \%(n=2)$ builders, $1.7 \%(n=2)$ tailors, and $0.8 \%(n=1)$ carpenters. Consequently, it was observed that while the majority of respondents were farmers, the highest level of education attended by the majority of respondents, $74.2 \%(\mathrm{n}=89)$, was primary school. The rest were secondary school leavers at $20.8 \%(n=25)$, respondents with tertiary certificates at $2.5 \%(n=3)$, and those that who attended any formal school at $2.5 \%(n=3)$.

\subsubsection{Caring and Satisfaction Rating}

Across the caring and satisfaction dimensions, the highest rated caring attribute was respect for patients' privacy of comfort dimension $(88.6 \%$; $\mathrm{M}=4.43 ; \mathrm{SD}=1.301)$, while the lowest rated caring attribute was patient teaching of clinical care dimension $(40.6 \% ; \mathrm{M}=2.03 ; \mathrm{SD}=0.898)$. Highest patient satisfaction was observed with the attribute of trust dimension $(90.6 \% ; \mathrm{M}=4.53 ; \mathrm{SD}=0.879)$, and lowest patient satisfaction occurred with the patient teaching aspect of education dimension $(37.4 \% ; \mathrm{M}=1.87 ; \mathrm{SD}=1.710)$. Table 2 shows detailed frequency results for caring and satisfaction.

Table 2. Frequencies for caring and satisfaction

\begin{tabular}{|c|c|c|c|c|}
\hline \multicolumn{5}{|c|}{ Range of standard deviation and mean scores for caring and satisfaction } \\
\hline & Lowest mean score & Standard deviation & Highest mean score & Standard deviation \\
\hline Caring & 2.03 & 0.898 & 4.43 & 1.301 \\
\hline Satisfaction & 1.87 & 1.710 & 4.53 & 0.879 \\
\hline
\end{tabular}

\subsubsection{Overall Rating of Quality of Care}

Table 3 tabulates the detailed frequency results for overall rating of caring quality.

Table 3. Frequencies for quality of care rating

\begin{tabular}{lll}
\hline & Number & $\%$ \\
\hline Quality of care rating & 23 & \\
Very good & 67 & 55.8 \\
Good & 25 & 20.8 \\
Average & 5 & 2.5 \\
Poor & 2 & 1.7 \\
Very poor & 2 & \\
\hline
\end{tabular}

\subsubsection{Correlation Between Caring and Patient Satisfaction}

Pearson product moment correlation revealed positive correlation of moderate strength between caring and patient satisfaction with the majority of correlations $(68 \% ; n=17)$ statistically significant $(r=.260$ to $.475 ; p<.005\{2$ tailed $;$; $=120$ ). Table 4 shows details of the correlation results between caring and patient satisfaction. 
Table 4. Pearson correlation among caring and patient satisfaction dimensions

\begin{tabular}{|c|c|c|c|c|c|c|}
\hline & & \multicolumn{5}{|l|}{ Satisfaction } \\
\hline & & $\begin{array}{l}1 . \quad \text { Nurse's } \\
\text { professional } \\
\text { skills }\end{array}$ & $\begin{array}{l}\text { 2. Respect for } \\
\text { patients } \\
\text { autonomy }\end{array}$ & $\begin{array}{l}\text { 3. Promotion } \\
\text { of patient trust }\end{array}$ & $\begin{array}{l}\text { 4. Nature of } \\
\text { nurse-patient } \\
\text { communication }\end{array}$ & $\begin{array}{l}\text { 5. Professional } \\
\text { proficiency }\end{array}$ \\
\hline \multirow{5}{*}{ שֶ: } & $\begin{array}{l}\text { 1. Personal presence } \\
\text { of the nurse }\end{array}$ & $.45^{* *}$ & $.4 * *$ & $.3 * *$ & $.34 * *$ & $.28 * *$ \\
\hline & $\begin{array}{l}\text { 2. Caring by nurse's } \\
\text { creative use of self }\end{array}$ & $.38 * *$ & $.3 * *$ & $.22 *$ & $.14^{*}$ & $.21 *$ \\
\hline & $\begin{array}{l}\text { 3. Caring by } \\
\text { competence and } \\
\text { with confidence }\end{array}$ & $.47 * *$ & $.15^{*}$ & $.23 *$ & $.34 * *$ & $.36^{* *}$ \\
\hline & $\begin{array}{l}\text { 4. Presence and } \\
\text { being present partner } \\
\text { in patient care }\end{array}$ & $.41^{* *}$ & $.23^{*}$ & $.26^{* *}$ & $.30 * *$ & $.47 * *$ \\
\hline & $\begin{array}{l}\text { 5. Caring by } \\
\text { promotion of human } \\
\text { dignity }\end{array}$ & $.40 * *$ & $-.02 *$ & $.17^{*}$ & $.27 * *$ & $.38 * *$ \\
\hline
\end{tabular}

\subsection{Influence of Participants' Demographic Characteristics on Caring and Satisfaction}

\subsubsection{Age}

Pearson product moment correlation coefficient showed a negative correlation between age and caring $(r=-.231, p$ $<.05, \mathrm{~N}=120)$, and age and satisfaction $(r=-.248, \mathrm{p}<.05, \mathrm{n}=120)$. Thus, the older a respondent was in the sample, the less they were satisfied with caring.

\subsubsection{Gender}

Independent sample t-test showed that female respondents were more satisfied than male respondents, with statistically significant difference in satisfaction for female $(M=19.57, S D=2.812)$, against male $(M=17.81$, $\mathrm{SD}=5.493), t(118)=-1.970, p=<.005$, 2-tailed. Mean difference $=-1.766,95 \% C I:-3.541$ to .009 ; eta squared $=$ 0.03 . For caring, no significant difference in caring rating was observed between male and female respondents.

\subsubsection{Marital Status}

The independent sample t-test found that unmarried respondents rated caring higher than married respondents, with statistically significant difference in caring rating for the unmarried $(\mathrm{M}=18.88, \mathrm{SD}=3.626)$, against the married $(\mathrm{M}=17.96, \mathrm{SD}=3.401), t(118)=-1.286, p=<.005,2$-tailed. Mean difference $=-.919,95 \%$ CI: -2.334 to .496 ; eta squared $=0.01$. For satisfaction, there was no significant difference in the rating between married and unmarried respondents.

\subsubsection{Education}

Independent sample t-test showed that more educated respondents (secondary/higher) rated caring higher than the less educated respondents (primary/lower), with statistically significant difference in caring rating for the more educated $(\mathrm{M}=18.95, \mathrm{SD}=3.558)$, against the less educated $(\mathrm{M}=17.98, \mathrm{SD}=3.431), t(118)=-1.302, p=<.005$, 2-tailed. Mean difference $=-.972,95 \%$ CI: -2.451 to .507 ), eta squared $=0.01$. However, for satisfaction, there was no significant difference in the rating between the less educated and the more educated.

\section{Phase Two (Qualitative Phase)}

This was a follow-up supplementary phase. The phenomenological approach (Denzin \& Lincoln, 2013) was used to explore and describe patients' experiences of care. Kerwin-Boudreau and Butler-Kisber (2016) explain that the phenomenological approach involves verbal extraction of important statements from participants, through the researcher's interpretation, making meanings out of them, organizing the meanings into themes, then clarifying the themes in a rich written description. 


\subsection{Study Participants and Setting}

Two participants (highest and lowest satisfied participants) who participated in the initial survey were purposively selected and followed up with semi-structured individual interviews. Both interviews were conducted in places chosen by the participants. A small sample was used as the qualitative data and results to elaborate on or explain the initial quantitative findings (Creswell, 2015: 37-9; Ivankova, 2015: 133; Morgan, 2014: 157-161).

\subsection{Data Collection}

An interview guide was used. The first key question asked, 'How was nursing care like for you during the last hospitalization?' Probes and follow-up questions were used to encourage the participants to clarify points, say more, or to re-focus the direction of the interview. With the participants' consent, the interviews were audio-taped. Each interview lasted 30 minutes (Grove, Burns, \& Gray, 2013).

\subsection{Data Analysis}

Data were analyzed by theming process as described by Giorgi (2009). The method seeks to explore the meaning of a phenomenon by identifying themes from the participants' lived experiences. By using this approach, the transcripts were first read through several times to get a sense of the whole. Next, the transcripts were re-read to discriminate meaning units and clarify them in relation to the caring phenomenon. Then, the identified meaning units were transformed into nursing language with emphasis on caring phenomenon.

\subsection{Findings}

One central theme was identified: perceived quality of caring was experienced by patients when nurses demonstrated presence and professional proficiency. It appeared that such a caring quality perception occurred as a result of trust that patients developed towards nurses. A lack of such trust was identified by Shan et al., (2016) as a cause for patient dissatisfaction. By being present with the patients and demonstrating proficiency when intervening with them, the nurses instilled a sense of trust in the patients, leading to high perceptions towards nurses' care. Similarly, patients lost trust in nurses and perceived them as uncaring when the nurses demonstrated absence, a lack of empathy, and emotional disconnectedness. The quotes below attest to these observations as narrated by the participants:

'...the care was very nice... I was given bed immediately I arrived in the ward. Perhaps just almost five minutes, everything was going well. ${ }^{72} \ldots$ No doubt, they knew what they were doing ... ${ }^{257}$... that is why I did not bother to ask why they took my blood samples, or deny them the ${ }^{261}$ samples...'

'...For me, the nurses were not reliable. I did not trust them... ${ }^{542}$... because I saw that what they did to me was somehow cruel. ...during the night shift, they could not be seen. For sure they went to sleep because throughout the night, they could not be $e^{435}$ seen in the ward. They only came when a new patient arrived... ${ }^{436}$...not for patients already in the ward. For those already in the ward, once they give you ${ }^{440}$ medicine in the evening, you won't see them again until the next morning. ${ }^{441}$...'

A patient's experiences during a caring moment are critical for the patient to develop trust. Murray and McCrone (2015: 3-23) suggest that conscious effort by the nurse may be necessary to help the patient develop trust. Morals and ethics might be critical to offset power imbalances associated with patients' exposure (Meyer et al., 2012). Creating an enabling caring environment might be essential to promote flourishing antecedents that foster development and trust. Such antecedents include, but are not limited to, demonstrations of professional expertise (McCabe \& Sambrook, 2014; Chowdhurry, 2012), good reputation (Nilsson \& Mattes, 2015), demonstrations of integrity through honesty, loyalty, fairness and reliability (McCabe \& Sambrook, 2014), communication (Nilsson \& Mattes, 2015; McCabe \& Sambrook, 2014; Chowdhurry, 2012), personality traits (Nilsson \& Mattes, 2015), and shared values (Chowdhurry, 2012).

\subsection{Demonstration of Caring Presence by Nurses Was Experienced by Patients as an Expression of Caring}

Watson (2008: 34) describes caring presence in line with a caring moment. It involves enabling and sustaining the nurses' own beliefs and those of the patient, being present to meet the patients' needs, thereby instilling hope and trust in the patients. The nurse invokes special competencies such as nurse-patient connection (Watson, 2008: 34; Kostovich, 2012: 169), therapeutic silence (Watson, 2008: 34; Hooper, 2013), nurse-patient sharing of stories and experiences (Kostovich, 2012: 169; Hooper, 2013), appropriate eye contact (Watson, 2008: 34; Kostovich, 2012: 169), respecting life, incorporating patients' values and beliefs in the care plan, promoting patients' growth, avoiding objectifying patients (Watson, 2008: 34), therapeutic touch, attentiveness, smiling, sense of humor, centering, and positive body posture (Kostovich, 2012: 169). These competencies make caring presence an integral aspect of nursing care (Mohammadipour, Atashzadeh-Shoorideh, Parvizy, \& Hosseini, 2017). Narratives 
from participants' experiences in this study show that when the nurses were present in the ward, patients were promptly attended to. The following participants' narratives attest to these observations:

'... I was well received ${ }^{44}$...to the extent that the nurses showed eagerness to assist me and actually they assisted $m e^{48}$ to the best of how they knew their job. ${ }^{49} \ldots$

'... When they spoke, they had manners. They spoke well enough making sure that I should ${ }^{376}$ understand... ${ }^{377}$ You know how a person behaves when sick... ${ }^{381}$ If you shout at him/her, he/she wouldn't care... ${ }^{385}$... but the nurses might know what they are doing, while the patient might not know. ${ }^{389}$ Sometimes as a patient you act abnormally. The nurses tried their best to make sure that $I^{390}$ understood... 391

Demonstrating respect towards patients is an important aspect of patient care (Chadwick, 2012: 187-191). Respect for patients involves protecting their physical privacy (Warner et al., 2012: 86-92). Unnecessary exposure of patients during intimate procedures constitutes a breach of patient privacy (Lin et al., 2013: 168-177). It is dehumanizing and embarrassing. Careless behaviors and humiliating actions that compromise patients' respect and dignity have been reported within the healthcare profession. Findings in a study by Willassen, Blomberg, Von-Post and Lindwall (2015: 688) showed that healthcare providers demonstrate humiliating behavior that strip patients of their dignity. These included rendering the patients invisible, ignoring the patients' complaints, treating the patients as objects, speaking negatively to and about the patients, and blaming the patients for their health situation.

4.6 Demonstration of Professional Proficiency by Nurses Was Experienced by Patients as an Expression of Caring

Participants' narratives show that when nurses demonstrated competence, the patients perceived a quality of care. Nurses' demonstration of professional knowledge and skills was an indication of proficiency and quality caring (Chang, Yang, \& Yuan, 2014: 124). In other studies, an inability to demonstrate competence in healthcare delivery accounted for about 12\% of total patients who expressed dissatisfaction with healthcare (Shan et al. 2016). Regarding nurses' demonstration of knowledge and skills, participants' statements in this study showed that patients found nurses to be knowledgeable and skillful.

'...No doubt, they knew what they were doing. ${ }^{257}$ That is why I did not bother to ask why they took my blood samples, or deny them the $e^{261}$ samples. After all, the treatment came after the tests and my aim was to be treated and $^{262}$ get better. That's what I was interested in... "263

Those equipments, no I was not put on oxygen... ${ }^{552}$ but thermometer, yes! They were coming to measure my temperature in my armpits... ${ }^{556}$ She could look at the readings...${ }^{56}$ and then leave without saying anything...

Clinical competence is an essential element of quality caring, but it would not exist without professional knowledge and skills (Shrestha et al., 2013: 205-212). Professional knowledge and skills were found to correlate positively with competence, resulting in improved practice among nurses caring for children in Nepal (Shrestha et al., 2013: 205-212), diabetic patients in Jordan (Yacoub et al., 2014: 255-262), and oncology care in Vietnam (Nguyen et al., 2014: 448-456). The patients' perceptions of the improved care might have resulted from their trust in the nurses (Cross, Roe \& Wang, 2014: 560-565). In critical care settings, clinical competence is vital for monitoring a patient's condition (Atkinson, 2013), as well as operating specialized medical equipment. Inadequate clinical competence in continuous renal replacement therapy, for example, was found to be the cause for unwarranted change of filters, removal of machines, and failure to troubleshoot equipment; resulting in adverse effects for the patients (Przybyl et al., 2015: 135-147). Nurses' demonstration of competence in various clinical skills, including operating medical equipment, was a good indication of the quality of care they rendered to patients.

\section{Phase Three: Interpretation, Integration and Discussion of Results}

Results obtained in the quantitative phase suggest that the majority of patients were highly satisfied. Nurses' respect for patients' privacy and the nurses' presence were scored highly. Patient education (explanation and information giving) was poorly rated in both caring and satisfaction. These findings are consistent with previous studies where nurses were rated high at caring for respecting patient privacy, and low for not giving treatment-related information (Carlucci et al., 2013; Finkel et al., 2012). Respecting patient privacy is a critical step towards delivering dignified patient care. According to Li et al., (2013), unnecessary patient exposure during physical examination causes a lot of embarrassment to the patient, thereby undermining patient dignity. Safeguarding patient privacy is not only a caring issue; it is also a constitutional provision.

The nurses' physical presence in the ward reassures patients of prompt attention (Okoro \& Odedina, 2016). However, the nurses' presence as a caring concept goes beyond their mere physical presence. It entails emotional and spiritual connectedness between the nurse and the patient (Watson 2008: 34; Kostovich, 2012: 169). This 
connectedness propels the nurses' intentionality to caring and the patients' participatory willingness towards care interventions. In this study, it was found that the majority of patients were highly satisfied with caring with regard to the nurses' presence. This could be attributed to the fact that the nurses were well connected with patients, or that the patients had few expectations from the nurses.

\section{Conclusion: Caring and Satisfaction}

In conclusion, the findings of this study have shown that in general, quality of caring was high at the district hospital and patients were highly satisfied with the caring. Critical to influencing the patients' satisfaction were nurses' presence and professional proficiency. By using the mixed methods design, the study has broadened and deepened our understanding of patient satisfaction with caring at the district hospital in Malawi more than a single method alone would have done.

\section{Ethical Considerations}

Ethical clearance was obtained from the Research Ethics Committee (REC: 01-246-2015) and the Higher Degrees Committee (HDC: 01-164-2015) of the Faculty of Health Sciences at the University of Johannesburg. Permission to conduct the study was obtained from the National Health Sciences Research Committee (NHSRC) at the Ministry of Health of the Malawi government (protocol \# 15/12/1520), and from the district health officer. Further permission to gain access to the wards and participants was granted by nurses-in-charge in the participating wards. Participants' rights regarding their voluntary participation, withdrawal, privacy and confidentiality in the study were firmly upheld.

\section{Limitations of the Study}

The main limitation of this study was the underrepresentation of male participants. The use of two participants as part of the qualitative exploratory part can be seen as a further limitation.

\section{Competing Interests Statement}

The authors declare that there are no competing or potential conflicts of interest.

\section{References}

Aiken, L. H., Sermeus, W., Van den Heed, K., Sloane, D. M., Busse, R., McKee, M., ... Kutney-Lee, A. (2012). Patient safety, satisfaction and quality of care: cross-sectional surveys of nurses and patients in 12 countries in Europe and the United States. The British Medical Journal, 344, e1717. https://doi.org/10.1136/bmj.e1717

Al-Abri, R., \& Al-Balushi, A. (2014). Patient satisfaction survey as a tool towards quality improvement. Oman Medical Journal, 29(1), 3-7. https://doi.org/10.5001/omj.2014.02

Atkinson, D. (2013). Nursing Observation and Assessment of Patients in the Acute Medical Unit, PhD Thesis, University of Salford.

Azizi-Fini, I., Mousavi, M., Mazroui-Sabdani, A., \& Adib-Hajbaghery, M. (2012). Correlation between nurses' caring Behaviours and Patients' Satisfaction. Nursing and Midwifery Studies, 1, 36-40. https://doi.org/10.5812/nms.7901

Baillie, L., Cox, J., \& Merritt, J. (2012). Caring for older people with dementia in hospital: part one. Nursing Older People, 24(8), 33-37. https://doi.org/10.7748/nop2012.10.24.8.33.c9312

Baillie, L., \& Gallagher, A. (2011). Respecting dignity in care in diverse care settings: Strategies of UK nurses. International Journal of Nursing Practice, 17, 336-341. https://doi.org/10.1111/j.1440-172X.2011.01944.x

Balfe, M., Brugha, R., Smith, D., Sreenan, S., Doyle, F., \& Conroy, R. (2013). Considering quality of care for young adults with diabetes in Ireland. Bio-Med Central health Services Research. https://doi.org/10.1186/1472-6963-13-448

Bjertnaes, O. A., Sjetne, I. S., \& Iversen, H. H. (2012). Overall patient satisfaction with hospitals: effects of patient reported experiences and fulfilment of expectations. The British Medical Journal Quality and Safety, 21(1), 39-46. https://doi.org/10.1136/bmjqs-2011-000137

Blackstock, O., Addison, D., Brennam, J., \& Alao, O. (2012). Trust in primary care providers and antiretroviral adherence in urban HIV clinic. Journal of Healthcare for the Poor and Undeserved, 23(1), 88-89. https://doi.org/10.1353/hpu.2012.0006

Bohnert, A., Zivin, K., Welsh, D., \& Kilbourne, A. (2011). Ratings of patient-provider communication among veterans: serious mental illness, substance abuse disorders and the moderating role of trust. Health Communication, 26, 267-272. https://doi.org/10.1080/10410236.2010.549813 
Brumpton, B. M., Leivseth, L., Romundstad, P. R., Langhammer, Y. C., Camargo Jr, C. A., \& Mai, X. (2013). The joint association of anxiety, depression, and obesity with incident asthma in adults: the HUNT study. International Journal of Epidemiology, 42, 1455-1463. https://doi.org/10.1093/ije/dyt151

Cameron, R. (2011). Mixed methods research: the five P's framework. The Electronic Journal of Business Research Methods, 9(2), 96-108.

Carlucci, D., Renna, P., \& Schiuma, G. (2013). Evaluating service quality as antecedents to out-patients' satisfaction using back propagation neural network. Health Care Management Sciences, 16(1), 37-44. https://doi.org/10.1007/s10729-012-9211-1

Chadwick, A. (2012). A dignified approach to improving the patient experience: promoting privacy, dignity and respect through collaborative training. Nurse Education in Practice. 2012(4), 187-191. https://doi.org/10.1016/j.nepr.2011.12.006

Chang, Z. X., Yang, G. H., \& Yuan, W. (2014). Competency-based management effects on satisfaction of nurses and patients. International Journal of Nursing Sciences, 1(2014), 121-125. https://doi.org/10.1016/j.jijnss.2014.02.001

Chowdhury, P. P. (2012). Antecedents and Consequences of Trust and Commitment in B2B Relationship: A Review of Literature.

Cossette, S., Cote, J. K., Pepin, J., Ricard, N., \& D'Aoust, L. X. (2006). A dimensional structure of nurse patient interactions from a caring perspective: refinement of the caring Nurse-patient interactions scale (CNPI-Short Scale). Journal of Advanced Nursing, 55(2), 198-214. https://doi.org/10.1111/j.1365-2648.2006.03895.x

Creswell, J. W. (2014). Research Design Qualitative, Quantitative and Mixed Methods Approaches (4th ed.). Sage, California.

Cross, H. H., Roe, C. A., \& Wang, D. (2014). Staff nurse confidence in their skills and knowledge and barriers to caring for patients with ostomies. Journal of Wound Ostomy Continence Nursing, 41(6), 560-565. https://doi.org/10.1097/WON.0000000000000065

Denzin, N. K., \& Lincoln, Y. S. (2013). Strategies of a Qualitative Inquiry (4th ed.). Sage. California.

De Vos, A. S., Strydom, H., Fouche, C. B., \& Delport, C. S. L. (2011). Research at grassroots for the social sciences and human service professions (4th ed.). Pretoria: Van Schaik.

Elder, K., Ramamonjiarivero, Z., Piper, C., Horn, W., Gilbert, K., Hullert, S., \& Allison, J. (2012). Trust, medication adherence and hypertension control in Southern African men. American Journal of Public Health, 102(12), 2242-2245. https://doi.org/10.2105/AJPH.2012.300777

Ferri, P., Muzzalupo, J., \& Lorenzo, R. D. (2015). Patients' perception of dignity in an Italian general hospital: a cross-sectional analysis. Bio-Med Central Health Services Research. https://doi.org/10.1186/s12913-015-0704-8

Finkel, H. F., Adelekan, A. M., Marcus, T. S., \& Wolvaardt, G. (2012). Assessment of service quality of public ant-retroviral treatment (ART) clinics in South Africa: a cross-sectional study. Bio-Medical Central Health Services Research. https://doi.org/10.1186/1472-6963-12-228

Giorgi, A. (2009). The descriptive phenomenological method in psychology: A modified Husserlian approach. Pittsburg, PA: Duquesne University.

Gray, J., Grove, S., \& Sutherland, S. (2017). Burns and Grove's the practice of nursing research. Appraisal, synthesis and generation of evidence (8th ed.). St Louis, Missouri: Elsevier.

Grove, S. K., Burns, N., \& Gray J. R. (2013). Practice of nursing research: appraisal, synthesis and generation of evidence (7th ed.). St Louis Missouri: Elsevier.

Gupta, D., Markman, M., Rodeghier, M., \& Lis, C. G. (2012). The relationship between patient satisfaction with service quality and survival in pancreatic cancer. Patient preference and adherence, 6, 6765-77. https://doi.org/10.2147/PPA.S37900

Higgins, P. C., \& Prigerson, H. G. (2013). Caregiver evaluation of the quality of end of life care scale: the care giver's perceptions of patient care near death. PLOS ONE, 8(6), e66066. https://doi.org/10.1371/journal.pone.0066066

Hooper, V. D. (2013). The caring presence of nursing: A qualitative focus. Journal of Perianesthesia Nursing, 28(5), 255-256. https://doi.org/10.1016/j.jopan.2013.08.002 
Iftikhar, A., Allah, N., Shadiullah, K., Habibullah, K., Muhammad, A. R., \& Muhammad, H. K. (2011). Predictors of patient satisfaction. Gomal Journal of Medical Sciences, 9(2), 183-189.

Iloh, G. U., Ofoedu, J., Njoku, P., Okafor, G., Amadi, A., \& Godswill-Uko, E. (2013). Satisfaction with quality of care received by patients without national health insurance attending a primary care clinic in a resource poor environment of a tertiary hospital in eastern Nigeria in the era of scaling up the Nigerian formal sector health insurance scheme. Annals of Medical and Health Sciences Research, 3(1), 31-37. https://doi.org/10.4103/2141-9248.109471

Ivankova, N. V. (2015). Mixed Methods Application in Action Research: From Methods to Community Action. California: Sage.

Jones, D., Carson, K., Bleich, S., \& Cooper, L. (2012). Patient trust in physicians and adoption of lifestyle behaviours to control high blood pressure. Patient Education and Counselling, 89, 57-62. https://doi.org/10.1016/j.pec.2012.06.003

Kerwin-Boudreau, S., \& Butler-Kisber, L. (2016). Deepening understanding in qualitative inquiry. The qualitative Report, 21(5), 956-971.

Kim, C. E., Shin, J., Lee, J., Lee, Y. J., Kim, M., Choi, A., Park, K. B., Lee, H., \& Ha, I. (2017). Quality of medical service, patient satisfaction and loyalty with a focus on inter-personal based medical service encounters and treatment outcomes: a cross-sectional multicentre study of complementary and alternative medicine (CAM) hospitals. Biomedical Central Complementary and Alternative Medicin. https://doi.org/10.1186/s12906-017-1691-6

Kobayashi, H., Takemura, Y., \& Kanda, K. (2011). Patient perceptions of nursing service quality: An applied model of Donabedian's structute-proces-outcome approach theory. Scandinavian Journal of Caring Sciences, 25(3), 419-425. https://doi.org/10.1111/j.1471-6712.2010.00836x.

Kostovich, C. T. (2012). Development and psychometric assessment of the Presence of Nursing Scale. Nursing Science Quarterly, 25(2), 167-175. https://doi.org/10.1177/0894318412437945

Kvist, T., Voutilainen, A., Mäntynen, R., \& Vehviläinen-Julkunen, K. (2014). The relationship between patient's perceptions and three factors: nursing staff, job satisfaction, organisations characteristics and patient's age. British Medical Central Health Services Research. https://doi.org/10.1186/1472-6963-14-466

Liljeroos, M., Agren, S., Jaarsma, T., \& Strömberg, A. (2014). Perceived caring needs in patient-partner dyads affected by heart failure: A qualitative study. Journal of Clinical Nursing, 23(19-20), 2928-2938. https://doi.org/10.1111/jocn.12588

Li, Y. P., Watson, R., \& Tsai, Y. F. (2013). Dignity in care in the clinical setting: A narrative review. Nursing Ethics, 20(2), 168-177. https://doi.org/10.1177/0969733012458609

Lin, Y. K., \& Lin, C. J. (2011). Factors predicting patient's perception of privacy and satisfaction for emergency care. Emergency Medical Journal, 28(7), 604-608. https://doi.org/10.1136/emj.2010.093807

Lin, Y. P., \& Tsai, Y. F. (2011). Maintaining patients' dignity during clinical care: a qualitative interview study. Journal of Advanced Nursing, 67(2), 340-348. https://doi.org/10.1111/j.1365-2648.2010.05498.x

Lin, Y. P., Tsai, Y. F., \& Chen, H. F. (2011). Dignity in care in the hospital setting from the perspectives of patients in Taiwan: a descriptive qualitative study. Journal of Clinical Nursing, 2011(20), 794-801. https://doi.org/10.1111/j.1365-2702.2010.03499.x

McCabe, T. J., \& Sambrook, S. (2014). The antecedents, attributes and consequences of trust among nurses and nurse managers: a concept analysis. International Journal of Nursing Studies, 51(5), 815-827. https://doi.org/10.1016/j.ijnurstu.2013.10.003

Meyer, S., Ward, P., \& Jiwa, M. (2012). Does prognosis and socioeconomic status impact on trust in physicians? Interviews with patient with coronary disease in South Australia. British Medical Journal Open 2. https://doi.org/10.1136/bmjopen-2012-001389

Mohammadipour, F., Atashzadeh-Shoorideh, F., Parvizy, S., \& Hosseini, M. (2017). Concept development of nursing presence: application of Schwartz-Barcott and Kim's hybrid model. Asian Nursing Research, 11(2017), 19-29. https://doi.org/10.1016/j.anr.2017.01.004

Murray, B., \& McCrone, S. (2015). An integrative review of promoting trust in the patient-primary care provider relationship. Journal of Advanced Nursing, 71(1), 3-23. https://doi.org/10.1111/jan.12502 
Nguyen, L. T., Yates, P., \& Osborne, Y. (2014). Palliative care knowledge, attitudes and perceived self-competence of nurses working in Vietnam. International Journal of Palliative Nursing, 20(9), 448-456. https://doi.org/10.12968/ijpn.2014.20.9.448

Nilsson, M., \& Mattes, J. (2015). The spatiality of trust: Factors influencing the creation of trust and the role of face to face contacts. European Management Journal. https://doi.org/10.1016/j.emj.2015.01.002

Okoro, O., \& Odedina, F. T. (2016). Improving medication adherence in African-American women living with HIV/AIDS: Leveraging the provider role and peer involvement. AIDS Care - Psychological and Socio-Medical Aspects of AIDS/HIV, 28(2), 179-185. https://doi.org/10.1080/09540121.2015.1071771

Papastavrou, E., Efstathiou, G., Tsangari, H., Suhonen, R., Leon-Kilpi, H., Patiraki, E., Karlou, C., Balogh, Z., Palese, A., Tomietto, M., Jarosova, D., \& Merkouris, A. (2012). A cross-cultural study of the concept of caring through behaviours: patients' and nurses' perspectives in six different EU countries. Journal of Advancing Nursing, 68(5), 1026-1037. https://doi.org/10.1111/j.1365-2648.2011.05807.x

Phillips-Salimi, J. E., Haase, J. E., \& Kooken, W. C. (2011). Connectedness in the context of patient-provider relationship: a concept analysis. Journal of Advanced Nursing, 68(1), 230-244. https://doi.org/10.1111/j.1365-2648.2011.05763.x

Przybyl, H., Androwich, I., \& Evans, J. (2015). Using high fidelity simulation to assess knowledge, skills and attitudes in nurses performing CRRT. Nephrology Nursing Journal, 42(2), 135-147.

Qiuting, C. A. O. (2013). Humanistic caring: the core of nursing. Journal of Medical Colleges of PLA, 28, 125-128. https://doi.org/10.1016/S1000-1948(13)60026-X

Rama, M., \& Kanagaluru, S. K. (2011). A study on the satisfaction of patients with reference to hospital services. International Journal of Business Economics \& Management Research, 1(3), 16-25.

Risser, N. L. (1975). Development of an instrument to measure patient satisfaction with nurses and nursing care in primary care settings. Nursing Research, 24(1), 45-52. https://doi.org/10.1097/00006199-197501000-00011

Rouhi, G., Asayesh, H., Rahmani, H., \& Abbasi, A. (2011). Job satisfaction and organizational commitment among nursing staff: A study from Golestan, Iran. PAYESH Health Monitor, 10(2), 285-292.

Shan, L., Li, Y., Ding, D., Wu, Q., Liu, C., Jiao, M., Hao, Y., Han, Y., Gao, L., Hao, J., Wang, L., Xu, W., \& Ren, J. (2016) Patient Satisfaction with Hospital Inpatient Care: Effects of Trust, Medical Insurance and Perceived Quality of Care. PLoS ONE, 11(10), e0164366. https://doi.org/10.1371/journal.pone.0164366

Shrestha, S., Petrini, M., \& Turale, S. (2013). New born care in Nepal: the effects of an educational intervention on nurses' knowledge and practice. International Nursing Review, 60, 205-212. https://doi.org/10.1111/inr.12017

Smith, M. C. (2013). Caring: An essential human need. In M. C. Smith, M. C. Turkle, \& Z. R. Wolf, (Eds.), Caring in Nursing Classics: An Essential Resource. New York, NY: Springer. 10036.

Souliotis, K., Agapidaki, E., Peppou, L. E., Tzavara, C., Samoutis, G., \& Theodorou, M. (2016). Assessing patient participation in health policy decision-making in Cyprus. International Journal of Health Policy and Management, 5(8), 461-466. https://doi.org/10.15171/ijhpm.2016.78

Sumner, J. (2012). Communication as moral caring in nursing: The moral construct of caring in nursing as communicative action. International Journal for Human Caring, 16(2), 20-27. https://doi.org/10.20467/1091-5710.16.2.20

Tadd, W., Hillman, A., Calnan, S., Calnan, M., Bayer, T., \& Read, S. (2011). Right place - wrong place: Dignity in the acute care of older people. Quality in Ageing and Older Adults, 12(1), 33-43. https://doi.org/10.5042/qiaoa.2011.0143

Taheri, L., Jahromi, M. M., \& Hojat, M. (2015). Comparison patients and staffs satisfaction in general versus special wards of hospitals of Jahrom. Global Journal of Health Science, 7(6), 95-100. https://doi.org/10.5539/gjhs.v7n6p95

Wu, H. L., \& Volker, D. L. (2012). Humanistic nursing theory: Application to hospice and palliative care. Journal of Advanced Nursing, 68(2), 471-479. https://doi.org/10.1111/j.1365-2648.2011.05770.x

Warner, A., Saxton, A., Indig, D., Fahy, K., \& Hovart, L. (2012). Women's experience of early pregnancy care in the emergency department: A qualitative study. Australian Emergency Nursing Journal, (15), 86-92. https://doi.org/10.1016/j.aenj.2012.02.002

Watson, J. (2008). Nursing: The Philosophy and Science of Caring (rev. ed.). Boulder: University Press of 
Colorado.

Watson, J. (1979). Nursing: The Philosophy and Science of Caring. In M. C. Smith, M. C. Turkle, \& Z. R. Wolf, (Eds.), Caring in Nursing Classics: An Essential Resource. New York, NY: Springer. 10036.

Willassen, E., Blomberg, A. C., Von-Post, I., \& Lindwall, L. (2015). Student nurses' experiences of undignified caring in perioperative practice - part ii. Nursing Ethics, 22(6), 688-699. https://doi.org/10.1177/0969733014542678

Yacoub, M. I., Demeh, W. M., Darawad, M. W., Barr, J. L., Saleh, A. M., \& Saleh, M. Y. (2014). An assessment of diabetes related knowledge among registered nurses working in hospitals in Jordan. International Nursing Review, 2014(61), 255-262. https://doi.org/10.1111/inr.12090

Zgierska, A., Rabago, D., \& Miller, M. M. (2014). Impact of patient satisfaction ratings on physicians and clinical care. Patient Preference and Adherence, 2014(8), 437446. https://doi.org/10.2147/PPA.S59077

\section{Copyrights}

Copyright for this article is retained by the author(s), with first publication rights granted to the journal.

This is an open-access article distributed under the terms and conditions of the Creative Commons Attribution license (http://creativecommons.org/licenses/by/4.0/). 